\title{
Distinguishing testicular torsion from torsion of the appendix testis by clinical features and signs in patients with acute scrotum
}

This article was published in the following Dove Press journal:

Research and Reports in Urology

28 August 2017

Number of times this article has been viewed

\author{
Naoyuki Fujita' \\ Mitsuhiro Tambo' \\ Takatsugu Okegawa' \\ Eiji Higashihara ${ }^{2}$ \\ Kikuo Nutahara' \\ 'Department of Urology, ${ }^{2}$ Department \\ of Autosomal Dominant Polycystic \\ Kidney Disease (ADPKD) Research, \\ Kyorin University School of Medicine, \\ Mitaka, Tokyo
}

Purpose: Many physicians encounter confusion and difficulty in distinguishing testicular torsion (TT) from torsion of the appendix testis (TAT) in patients with acute scrotum because of the overlapping signs and symptoms. The objective of our study was to evaluate the clinical features and signs that can help distinguish TT from TAT.

Patients and methods: We performed a retrospective study of patients with surgically confirmed TT and TAT at our institute from January 1990 to December 2013. Clinical findings, physical examination findings, climatic conditions, laboratory data, and color Doppler ultrasound (CDUS) findings were compared between the TT and TAT groups.

Results: Seventy patients were included in this study ( 49 with TT and 21 with TAT). Patients with TT were significantly older than those with TAT $(p<0.001)$. The ambient temperature at onset was significantly lower in patients with TT than in patients with TAT $(p=0.038)$. Testicular swelling, high-riding testes, onset during sleep, high leukocyte counts, and high creatine phosphokinase levels were significantly more common in patients with TT than with TAT ( $p=0.021,0.032,0.006,0.003$, and 0.043 , respectively). Multivariate analysis showed that age and onset during sleep were significant independent factors for detection of TT. Eight patients (16.3\%) underwent preoperative CDUS evaluation, and an absent or decreased blood signal in the involved testes was significantly correlated with the presence of TT $(p=0.018)$.

Conclusion: In clinical features, age and onset during sleep might be helpful to distinguish TT from TAT. When supported by findings, urgent surgical exploration is warranted in patients with suspected TT based on symptoms and CDUS features.

Keywords: acute scrotum, testicular torsion, torsion of appendix testis, color Doppler ultrasound

\section{Introduction}

Acute scrotum is a urological emergency requiring prompt assessment. Differential diagnoses of acute scrotum include testicular torsion (TT), torsion of the appendix testis (TAT), epididymitis, and orchitis. The most common causes of acute scrotum, as seen in the emergency department, are TT, TAT, and epididymitis. ${ }^{1,2}$ TT and TAT are the most common causes for patients to undergo scrotal exploration for acute scrotum suspicious of TT. ${ }^{3-5}$ TT is an emergent medical condition, and restoration of blood supply in the involved testis must be achieved as soon as possible after onset of TT to salvage testicular tissue. TT initially obstructs venous return. Subsequent equalization of the venous and arterial pressures compromises arterial flow, resulting in testicular ischemia. The degree of ischemia depends on the duration of torsion and degree of rotation of the spermatic cord. In patients with TT, the spermatic cord shortens as it twists, whereby, the testis may appear to be situated higher within the affected scrotum.
Correspondence: Naoyuki Fujita

Department of Urology, Kyorin

University School of Medicine, 6-20-2

Shinkawa, Mitaka, Tokyo I8I-86II, Japan

Tel +814224755 I I

Fax +8I 42242843 I

Email nao7333ei@live.jp 
Because of venous congestion, the affected testis may also appear larger than the unaffected testis. Several symptoms and physical examination findings are associated with TT, and color Doppler ultrasound (CDUS) has been widely proposed as a helpful examination to diagnose TT. ${ }^{6,7}$ Furthermore, a seasonal variation has been implicated as a contributor to the development of TT, with lower temperatures associated with increased incidence. ${ }^{8}$ The appendix testis is a Müllerian duct remnant on the superior aspect of the testicle. When the appendix testis undergoes torsion, a hard, tender nodule may be palpable on the upper pole of the testicle, and a blue discoloration referred to as the "blue dot sign" may be visible in this area. However, scrotal edema develops rapidly and often obscures physical examination findings. TAT can be treated with analgesics, cooling, and reduced activity in almost all cases. Only a few boys will require surgical resection of the appendix testis for pain management.

Many physicians encounter confusion and difficulty in distinguishing TT from TAT in patients with acute scrotum because of overlapping signs and symptoms. The purpose of this study was to evaluate the clinical features and signs that can help distinguish TT from TAT in patients with acute scrotum.

\section{Materials and methods}

Patients who presented with acute scrotum and were subsequently diagnosed with surgically confirmed TT and TAT at our unit from January 1990 to December 2013 were retrospectively reviewed. Patients without TT or TAT, but with other surgically confirmed conditions, such as epididymitis and orchitis, were excluded. In all cases, clinical findings (age, duration of pain, onset during sleep, and fever), physical examination findings (side of the involved testis, testicular tenderness, testicular swelling, and high-riding testis), climatic conditions (ambient temperature, humidity, and barometric pressure), laboratory data [leukocyte count and creatine phosphokinase (CK) level], and CDUS findings were collected. CDUS was performed by senior radiologist to evaluate the acute scrotum in the daily clinical setting. Owing to the local policy during the study period, CDUS was not yet a part of the diagnostic workup of the acute scrotum. The findings on CDUS performed by a resident urologist on account of the absence of senior radiologist in the emergency department at night were excluded, because the sensitivity of CDUS for diagnosis of TT is highly dependent on the expertise and technique of the investigator. ${ }^{9}$ If causes of acute scrotum other than epididymitis and orchitis were diagnosed, immediate surgical exploration was performed. Duration of pain, patient age, ambient temperature, and leukocyte count were dichotomized as follows: duration of pain, $<24 \mathrm{vs} \geq 24$ hours; age, $\leq 12$ vs $>12$ years; ambient temperature, $<15^{\circ} \mathrm{C}$ vs $\geq 15^{\circ} \mathrm{C}$; and leukocyte count, $\leq 10^{4}$ vs $>10^{4}$ per mm. . $^{3,2,5,8,10,11}$ The cut off CK level was $167 \mathrm{IU} / \mathrm{L}$, which is the upper limit of the reference range at our institution. Data on climatic conditions at the time of onset were obtained from the Japan Meteorological Agency. ${ }^{12}$

Variables in the two groups were compared using the Mann-Whitney $U$-test. The independence of fitness of the categorical data was estimated using the chi-squared test and Fisher's exact test. Multivariate analysis was performed using logistic regression analysis. A $p$-value of $<0.05$ was considered statistically significant. All statistical analyses were performed using commercially available statistical software (PASW Statistics for Windows, version 18.0; SPSS Inc., Chicago, IL, USA). This study was approved by the Research Ethics Committee of the University of Kyorin, and the approving body deemed that patient consent was not necessary as this was a retrospective study without any intervention. To protect patient privacy, personal data were de-identified.

\section{Results}

Seventy patients, including 49 with TT (70.0\%) and 21 with TAT $(30.0 \%)$, were enrolled in the study. Table 1 summarizes patient characteristics including clinical findings, physical examination findings, climatic conditions, and laboratory data. Patients with TT were significantly older than those with TAT $(p<0.001)$. The ambient temperature at onset was significantly lower in patients with TT than in those with TAT $(p=0.038)$. There were no significant differences in the months or seasons of onset between patients with TT and those with TAT ( $p=0.145$ and 0.790 , respectively). Testicular swelling, high-riding testis, onset during sleep, high leukocyte counts, and high CK levels were significantly more common in patients with TT than in those with TAT ( $p=0.021$, $0.032,0.006,0.003$, and 0.043 , respectively). Multivariate analysis showed that age $(p=0.002)$ and onset during sleep ( $p=0.026)$ were significant independent factors for detection of TT (Table 2). Thirty-three patients with TT (67.3\%) had onset during sleep. The ambient temperature among these patients was significantly lower than that among patients without onset during sleep ( $p=0.032$; Table 3 ). Patients with TAT did not exhibit significant association between onset during sleep and ambient temperature $(p=0.266)$.

Eight patients $(16.3 \%)$, including five with TT and three with TAT, underwent CDUS evaluation before 
Table I Characteristics of patients with testicular torsion (TT) and torsion of appendix testis (TAT)

\begin{tabular}{|c|c|c|c|c|}
\hline Variables & & TT group, $n$ (\%) & TAT group n (\%) & $p$-value \\
\hline Patients & & 49 & 21 & \\
\hline \multicolumn{5}{|l|}{ Clinical findings } \\
\hline \multirow[t]{2}{*}{ Age (years) } & Mean \pm SD & $16.8 \pm 6.2$ & $\mathrm{II} .2 \pm 4.6$ & \\
\hline & Median [range] & $16[4-46]$ & $\mid I[|-2|]$ & $<0.001$ \\
\hline \multirow[t]{2}{*}{ Age } & $\leq 12$ years & $6(12.3)$ & $13(61.9)$ & \\
\hline & $>12$ years & $43(87.7)$ & $8(38.1)$ & $<0.001$ \\
\hline \multirow[t]{2}{*}{ Duration of pain } & $<24$ hours & $43(87.8)$ & I 8 (85.7) & \\
\hline & $\geq 24$ hours & $6(12.2)$ & $3(14.3)$ & 0.815 \\
\hline \multirow[t]{2}{*}{ Onset during sleep } & Yes & $33(67.3)$ & $7(33.3)$ & \\
\hline & No & $15(32.7)$ & $14(66.7)$ & 0.006 \\
\hline \multicolumn{5}{|l|}{ Climatic conditions } \\
\hline \multirow[t]{2}{*}{ Ambient temperature $\left({ }^{\circ} \mathrm{C}\right)$} & Mean \pm SD & $11.7 \pm 7.8$ & $16.4 \pm 9.9$ & \\
\hline & Median [range] & $9.8[-4.0-28.4]$ & $\mid 5.9[|.7-3| . \mid]$ & 0.038 \\
\hline \multirow[t]{2}{*}{ Ambient temperature } & $<15^{\circ} \mathrm{C}$ & $36(73.5)$ & $10(47.6)$ & \\
\hline & $\geq 15^{\circ} \mathrm{C}$ & $13(26.5)$ & II (52.4) & 0.037 \\
\hline \multirow[t]{4}{*}{ Seasons } & Spring (March to May) & $15(30.6)$ & $5(23.8)$ & \\
\hline & Summer (June to August) & $7(14.3)$ & $4(19.0)$ & \\
\hline & Autumn (September to November) & $10(20.4)$ & $6(28.6)$ & \\
\hline & Winter (December to February) & $17(34.7)$ & $6(28.6)$ & 0.790 \\
\hline \multirow[t]{2}{*}{ Humidity (\%) } & Mean \pm SD & $58.6 \pm 16.2$ & $58.7 \pm 17.0$ & \\
\hline & Median [range] & $63[16-83]$ & $60[23-8 I]$ & 0.901 \\
\hline \multirow[t]{2}{*}{ Barometric pressure $(\mathrm{mmHg})$} & Mean \pm SD & $1011.5 \pm 8.5$ & $1009.4 \pm 7.5$ & \\
\hline & Median [range] & $1011.5[986.0-1024.7]$ & $1009.2[994.0-1023.0]$ & 0.265 \\
\hline \multicolumn{5}{|l|}{ Physical examination } \\
\hline \multirow[t]{2}{*}{ Body temperature $\left({ }^{\circ} \mathrm{C}\right)$} & Mean \pm SD & $36.9 \pm 0.7$ & $36.8 \pm 0.5$ & \\
\hline & Median [range] & $36.8[35.5-39.8]$ & $37.0[35.8-37.7]$ & 0.756 \\
\hline \multirow[t]{2}{*}{ Body temperature } & $\leq 37.5^{\circ} \mathrm{C}$ & $44(89.8)$ & $20(95.2)$ & \\
\hline & $>37.5^{\circ} \mathrm{C}$ & $5(10.2)$ & I (4.8) & 0.456 \\
\hline \multirow[t]{2}{*}{ Laterality } & Left & $35(71.4)$ & $12(57.1)$ & \\
\hline & Right & $14(28.6)$ & $9(42.9)$ & 0.243 \\
\hline \multirow[t]{2}{*}{ Diffuse tenderness } & Yes & $43(87.8)$ & $18(85.7)$ & \\
\hline & No & $6(12.2)$ & $3(14.3)$ & 0.815 \\
\hline \multirow[t]{2}{*}{ Testicular swelling } & Yes & $39(79.6)$ & II (52.4) & \\
\hline & No & $10(20.4)$ & $10(47.6)$ & 0.021 \\
\hline \multirow[t]{2}{*}{ High-riding testis } & Yes & $30(6 \mid .2)$ & $7(33.3)$ & \\
\hline & No & $19(38.8)$ & $14(66.7)$ & 0.032 \\
\hline \multicolumn{5}{|l|}{ Laboratory data } \\
\hline \multirow[t]{2}{*}{ Leukocyte counts $\left(\mathrm{mm}^{3}\right)$} & Mean \pm SD & $11944 \pm 3702$ & $9223 \pm 2648$ & \\
\hline & Median [range] & 11300 [5300-21900] & $8800[5600-14900]$ & 0.003 \\
\hline \multirow[t]{2}{*}{ Leukocyte counts } & $\leq 10^{4} / \mathrm{mm}^{3}$ & $16(32.7)$ & I5 (7I.4) & \\
\hline & $>10^{4} / \mathrm{mm}^{3}$ & $33(67.3)$ & $6(28.6)$ & 0.003 \\
\hline \multirow[t]{2}{*}{ Creatine phosphokinase (IU/L) } & Mean \pm SD & $849 \pm 4418$ & $|34 \pm 8|$ & \\
\hline & Median [range] & $\mid 49$ [57-3| |07] & $124[2-408]$ & 0.106 \\
\hline Creatine phosphokinase & $\leq 167 \mathrm{IU} / \mathrm{L}$ & $30(6 \mid .2)$ & $18(85.7)$ & \\
\hline & $>167 \mathrm{IU} / \mathrm{L}$ & $19(38.8)$ & $3(14.3)$ & 0.043 \\
\hline Color Doppler ultrasound & & & & \\
\hline Absent or decreased & Yes & $5(100)$ & $0(0)$ & \\
\hline Blood signal & No & $0(0)$ & $3(100)$ & 0.018 \\
\hline Missing & & 44 & 18 & \\
\hline
\end{tabular}

surgical exploration. All patients with TT showed absent or decreased blood signal in the involved testis, whereas none of the patients with TAT showed this finding. CDUS findings were significantly correlated with the presence of TT $(p=0.018)$.
Six patients with TT (12.2\%) underwent orchiectomy because a nonviable testis was found during the surgical exploration. There was no significant difference in age between the orchiectomy and salvaged-testes groups $(p=0.080)$. The time to operation in the orchiectomy group 
was significantly longer than that in the salvaged-testes group $(p=0.002)$. There was no significant difference in the degree of torsion between the orchiectomy and salvaged-testes groups $(p=0.483)$. The testes were salvaged in all patients who underwent an operation within 8 hours, with no relationship to the degree of torsion (Table 4).

\section{Discussion}

The incidence of TT exhibits two peaks: a small peak during the newborn period and a much larger peak around puberty (accounting for 65\% of all torsions). The rapidly increasing testicular mass in the peripubertal male increases the chance of testis rotation. ${ }^{3,13}$ With respect to TAT, several studies have reported that the age for peak incidence of TAT is significantly younger than that of peripubertal TT. ${ }^{13-15}$ Molokwu et al reported a significant difference in age between patients with TT and those with TAT (15 years vs 11 years, respectively;

Table 2 Odds ratio for testicular torsion in relation to various factors by multivariate logistic regression analysis

\begin{tabular}{lllll}
\hline Factor & & OR & $95 \% \mathbf{C l}$ & P-value \\
\hline Age & $\leq 12$ years & Ref & & \\
& $>12$ years & 12.30 & $(2.39-63.28)$ & 0.002 \\
Ambient temperature & $<15^{\circ} \mathrm{C}$ & Ref & & \\
& $\geq 15^{\circ} \mathrm{C}$ & 1.95 & $(0.43-8.74)$ & 0.383 \\
Onset during sleep & No & Ref & & \\
Testicular swelling & Yes & 6.13 & $(1.24-30.27)$ & 0.026 \\
& No & Ref & & \\
High-riding testis & Yes & 2.23 & $(0.39-12.85)$ & 0.369 \\
& No & Ref & & \\
Leukocyte counts & Yes & I.I7 & $(0.24-5.60)$ & 0.843 \\
& $\leq 10^{4} / \mathrm{mm}^{3}$ & Ref & & \\
Creatine phosphokinase & $\leq 167 \mathrm{IU} / \mathrm{L}$ & Ref & & 0.065 \\
& $>167 \mathrm{IU} / \mathrm{L}$ & 2.29 & $(0.38-13.70)$ & 0.365 \\
\hline
\end{tabular}

Abbreviations: $\mathrm{OR}$, odds ratio; $\mathrm{Cl}$, confidence interval; Ref, reference. $p<0.001$ ) and found that age $\leq 12$ years is a useful predictor of TAT. ${ }^{5}$ The multivariate analysis in the present study showed that age is one factor that is useful for detection of TT $(p=0.002)$.

Physical examination and clinical findings are helpful in distinguishing TT from TAT. In the present study, multivariate analysis revealed that onset during sleep was another factor useful for detecting TT on multivariate analysis $(p=0.026)$. A previous study reported that the sexual response cycle (excitement, plateau, orgasm, and resolution) in young males is associated with cremasteric contraction during sleep, which could result in TT. ${ }^{16}$ In the present study, the ambient temperature was significantly lower in patients with - than without - onset during sleep $(p=0.032)$, indicating that onset during sleep may be causally related to a low ambient temperature. Previous studies have reported that testicular tenderness, testicular swelling, a high-riding testis, pain duration $<24$ hours, and onset during sleep are positively associated with TT. ${ }^{2,13-15,17}$ Barbosa et al reported that nausea/ vomiting, testicular swelling, a high-riding testis, transverseoriented testis, hard testis, and absent cremasteric reflex are independent factors for detection of TT. ${ }^{6}$ These discordant results might have been affected by interobserver variability, the small study population, and the retrospective nature of the study.

A low ambient temperature may cause contraction of the cremasteric muscle, resulting in TT. ${ }^{18}$ Several studies have shown that TT is associated with a low ambient temperature $\left(<2^{\circ} \mathrm{C}\right.$ in Ireland, $<5^{\circ} \mathrm{C}$ in the $\mathrm{UK}$, and $<15^{\circ} \mathrm{C}$ in the US and Japan) and low humidity. ${ }^{5,7,8,10}$ Hoshino et al reported that $>75 \%$ of cases of TT occurred when the ambient temperature was $<15^{\circ} \mathrm{C}$ in Japan; ${ }^{8}$ this is similar to the rate found in the present study $\left(73.5 \%\right.$ of cases of TT occurred at $\left.<15^{\circ} \mathrm{C}\right)$.

Table 3 Characteristics of onset during sleep and without onset during sleep groups in patients with testicular torsion

\begin{tabular}{|c|c|c|c|c|c|c|}
\hline \multirow[t]{2}{*}{ Variables } & & \multicolumn{2}{|c|}{ Onset during sleep group } & \multicolumn{2}{|c|}{ Onset during waking group } & \multirow[t]{2}{*}{$p$-value } \\
\hline & & $\mathbf{n}$ & $\%$ & $\mathbf{n}$ & $\%$ & \\
\hline Patients & & 33 & & 15 & & \\
\hline \multirow[t]{2}{*}{ Age (years) } & Mean \pm SD & $15.8 \pm 4.9$ & & $18.6 \pm 8.2$ & & \\
\hline & Median [range] & $16[4-3 \mid]$ & & $18[11-46]$ & & 0.296 \\
\hline \multirow[t]{2}{*}{ Ambient temperature } & Mean \pm SD & $9.3 \pm 8.5$ & & $14.2 \pm 6.6$ & & \\
\hline & Median [range] & $8.7[-4.0-28.0]$ & & $12.4[6.2-28.4]$ & & 0.032 \\
\hline \multirow[t]{2}{*}{ Humidity (\%) } & Mean \pm SD & $58.4 \pm 16.2$ & & $59.2 \pm 16.8$ & & \\
\hline & Median [range] & 59 [23-83] & & 64 [16-79] & & $0.84 I$ \\
\hline \multirow[t]{2}{*}{ Barometric pressure $(\mathrm{mmHg})$} & Mean \pm SD & $1010.8 \pm 8.0$ & & $1012.9 \pm 9.5$ & & \\
\hline & Median [range] & $1010.3[996.7-1024.0]$ & & $10 \mid 4.5[986.0-1024.7]$ & & 0.234 \\
\hline \multirow[t]{2}{*}{ Body temperature $\left({ }^{\circ} \mathrm{C}\right)$} & Mean \pm SD & $36.8 \pm 0.5$ & & $36.9 \pm 0.9$ & & \\
\hline & Median [range] & $36.8[35.5-37.7]$ & & $36.8[36.0-39.8]$ & & 0.682 \\
\hline \multirow[t]{2}{*}{ Laterality } & Left & 23 & 69.7 & II & 73.3 & \\
\hline & Right & 10 & 30.3 & 4 & 26.7 & 0.797 \\
\hline
\end{tabular}


Table 4 Characteristics of orchiectomy group and salvaged testis group

\begin{tabular}{|c|c|c|c|c|c|c|}
\hline \multirow[t]{2}{*}{ Variables } & & \multicolumn{2}{|c|}{ Orchiectomy group } & \multicolumn{2}{|c|}{ Salvaged-testis group } & \multirow[t]{2}{*}{$p$-value } \\
\hline & & $\mathbf{n}$ & $\%$ & $\bar{n}$ & $\%$ & \\
\hline Patients & & 6 & & 43 & & \\
\hline \multirow[t]{2}{*}{ Age (years) } & Mean \pm SD & $19.2 \pm 3.1$ & & $16.5 \pm 6.5$ & & \\
\hline & Median [range] & $18[16-24]$ & & $15[4-46]$ & & 0.080 \\
\hline \multirow[t]{2}{*}{ Body temperature $\left({ }^{\circ} \mathrm{C}\right)$} & Mean \pm SD & $36.8 \pm 0.7$ & & $37.1 \pm 0.3$ & & \\
\hline & Median [range] & $37.2[36.6-37.3]$ & & $36.8[35.5-39.8]$ & & 0.311 \\
\hline Time to operation (hours) & Median [range] & $19.7[9.25-198]$ & & $5.4[1-22.2]$ & & 0.002 \\
\hline Degrees of torsion $\left({ }^{\circ}\right)$ & Median [range] & $360[180-360]$ & & $270[90-720]$ & & 0.483 \\
\hline \multirow[t]{2}{*}{ Laterality } & Left & 5 & 83.3 & 30 & 69.8 & \\
\hline & Right & 1 & 16.7 & 13 & 30.2 & 0.490 \\
\hline
\end{tabular}

These discordant results might have been affected by the differences in geography and location of occurrence (ie, indoor vs outdoor air temperature).

Furthermore, CDUS has been widely proposed as a helpful examination for diagnosis of TT. Several studies have shown that CDUS is $96 \%-100 \%$ sensitive and $75 \%-95 \%$ specific in diagnosing TT. ${ }^{7,19,20}$ In contrast, false-negative results might also occur with CDUS. ${ }^{7,9,19-21}$ There are several possible reasons for false-negative CDUS results. First, less experience on the part of the user and/or inadequate technical equipment may be contributing factors. ${ }^{9}$ Second, the maintenance of testicular perfusion in patients with an incomplete or nascent spermatic cord torsion may be associated with CDUS findings..$^{20,21}$ Experimental studies have shown that spermatic cord torsion of $<360^{\circ}$ may not compromise testicular blood flow. ${ }^{22-24}$ To increase the diagnostic yield for CDUS, Karmazyn et al reported that the presence of a coiled spermatic cord is an independent predictor of TT, and al Mufti et al reported that the cord-compression test is a useful tool for the diagnosis of TT. ${ }^{17,25}$ Further studies involving CDUS examination are necessary.

The duration of torsion symptoms and degree of torsion are correlated with the orchiectomy rate. Bartsch et al reported that irreversible ischemic injury to the testicular parenchyma may begin as early as 4 hours after occlusion of the cord. ${ }^{26}$ Tryfonas et al reported that torsion of $>360^{\circ}$ and $>24-h$ duration could result in testicular loss or severe atrophy. ${ }^{27}$ In the present study, all patients in the orchiectomy group had a $>8$-h time to operation. When TT is suspected, prompt surgical exploration is warranted.

Our study has some limitations. First, this study evaluated a small population and was retrospective in nature. Second, some of the variables (tenderness, swelling, and high-riding testis) are subject to interobserver variability. Third, CDUS data were quite limited in consequence of the local policy during the study period. More recently, CDUS was performed by trained urologist in the emergency department at night, and was included in diagnostic workup for acute scrotum as well. Prospective studies involving larger numbers of patients are needed to confirm these findings.

\section{Conclusion}

In clinical features, age and onset during sleep might be helpful for distinguishing TT from TAT in patients with acute scrotum. This supports the premise that urgent surgical exploration is warranted in patients suspected of TT on the basis of symptoms and CDUS findings.

\section{Author contributions}

NF, TO, and MT designed the research. NF and MT obtained the data. NF, TO, KN, and MT analyzed the data. NF and MT wrote the manuscript draft. $\mathrm{TO}, \mathrm{EH}$, and $\mathrm{KN}$ have made contributions providing a critical review of the manuscript for important intellectual content. All authors read and approved the final manuscript. All authors contributed toward data analysis, drafting and revising the paper and agree to be accountable for all aspects of the work.

\section{Disclosure}

The authors report no conflicts of interest in this work.

\section{References}

1. Beni-Israel T, Goldman M, Bar Chaim S, Kozer E. Clinical predictors for testicular torsion as seen in the pediatric ED. Am J Emerg Med. 2010;28(7):786-789.

2. Boettcher M, Bergholz R, Krebs TF, Wenke K, Aronson DC. Clinical predictors of testicular torsion in children. Urology. 2012;79(3):670-674

3. Anderson JB, Williamson RC. Testicular torsion in Bristol: a 25-year review. Br J Surg. 1988;75(10):988-992.

4. Van Glabeke E, Khairouni A, Larroquet M, Audry G, Gruner M. Acute scrotal pain in children: results of 543 surgical explorations. Pediatr Surg Int. 1999;15(5-6):353-357.

5. Molokwu CN, Somani BK, Goodman CM. Outcomes of scrotal exploration for acute scrotal pain suspicious of testicular torsion: a consecutive case series of 173 patients. BJU Int. 2011;107(6):990-993. 
6. Barbosa JA, Tiseo BC, Barayan GA, et al. Development and initial validation of a scoring system for diagnosing testicular torsion in children. J Urol. 2013;189(5):1859-1864.

7. Altinkilic B, Pilatz A, Weidner W. Detection of normal intratesticular perfusion using colour-coded duplex sonography obviates the need for scrotal exploration in patients with clinical suspicion of testicular torsion. J Urol. 2013;189:1853-1858.

8. Hoshino H, Abe T, Watanabe H, Katsuoka Y, Kawamura N. Correlation between atmospheric temperature and testicular torsion. Hinyokika Kiyo. 1993;39(11):1031-1033; discussion 1033-1034. Japanese.

9. Kalfa N, Veyrac C, Lopez M, et al. Multicenter assessment of ultrasound of the spermatic cord in children with acute scrotum. J Urol. 2007;177(1):297-301

10. Srinivasan AK, Freyle J, Gitlin JS, Palmer LS. Climatic conditions and the risk of testicular torsion in adolescent males. $J$ Urol. 2007;178(6):2585-2588.

11. Yang C, Song B, Tan J, Liu X, Wei GH. Testicular torsion in children: a 20-year retrospective study in a single institution. Scientific World J. 2011;11:362-368.

12. Japan Meteorological Agency [webpage on the Internet]. Weather, climate and earthquake information. Available from: http://www.jma. go.jp/jma/indexe.html. Accessed January 18, 2014.

13. Melekos MD, Asbach HW, Markou SA. Etiology of acute scrotum in 100 boys with regard to age distribution. J Urol. 1988;139(5):1023-1025.

14. Jefferson RH, Pérez LM, Joseph DB. Critical analysis of the clinical presentation of acute scrotum: a 9-year experience at a single institution. J Urol. 1997;158(3 Pt 2):1198-1200.

15. Kadish HA, Bolte RG. A retrospective review of pediatric patients with epididymitis, testicular torsion, and torsion of testicular appendages. Pediatrics. 1988;102(1 Pt 1):73-76.

16. Cass AS, Cass BP, Veeraraghavan K. Immediate exploration of the unilateral acute scrotum in young male subjects. J Urol. 1980;124(6): 829-832.
17. Karmazyn B, Steinberg R, Kornreich L, et al. Clinical and sonographic criteria of acute scrotum in children: a retrospective study of 172 boys. Pediatr Radiol. 2005;35(3):302-310.

18. Shukla RB, Kelly DG, Daly L, Guiney EJ.Association of cold weather with testicular torsion. Br MedJ (Clin Res Ed). 1982;285(6353):1459-1460.

19. Waldert M, Klatte T, Schmidbauer J, Remzi M, Lackner J, Marberger M. Color Doppler sonography reliably identifies testicular torsion in boys. Urology. 2010;75(5):1170-1174.

20. Pepe P, Panella P, Pennisi M, Aragona F. Does color Doppler sonography improve the clinical assessment of patients with acute scrotum? Eur J Radiol. 2006;60(1):120-124.

21. Kalfa N, Veyrac C, Baud C, Couture A, Averous M, Galifer RB. Ultrasonography of the spermatic cord in children with testicular torsion: impact on the surgical strategy. J Urol. 2004;172(4 Pt 2):1692-1695.

22. Bader TR, Kammerhuber F, Herneth AM. Testicular blood flow in boys as assessed at color Doppler and power Doppler sonography. Radiology. 1997;202(2):559-564.

23. Sanelli PC, Burke BJ, Lee L. Color and spectral Doppler sonography of partial torsion of the spermatic cord. AJR Am J Roentgenol. 1999;172(1):49-51.

24. Lee FT Jr, Winter DB, Madsen FA, et al. Conventional color Doppler velocity sonography versus color Doppler energy sonography for the diagnosis of acute experimental torsion of the spermatic cord. AJR Am J Roentgenol. 1996;167(3):785-790.

25. al Mufti RA, Ogedegbe AK, Lafferty K. The use of Doppler ultrasound in the clinical management of acute testicular pain. Br J Urol. 1995;76(5):625-627.

26. Bartsch G, Frank S, Marberger H, Mikuz G. Testicular torsion: late results with special regard to fertility and endocrine function. J Urol. 1980;124(3):375-378.

27. Tryfonas G, Violaki A, Tsikopoulos G, et al. Late postoperative results in males treated for testicular torsion during childhood. J Pediatr Surg. 1994;29(4):553-556.
Research and Reports in Urology

\section{Publish your work in this journal}

Research and Reports in Urology is an international, peer-reviewed, open access journal publishing original research, reports, editorials, reviews and commentaries on all aspects of adult and pediatric urology in the clinic and laboratory including the following topics: Pathology, pathophysiology of urological disease; Investigation and treatment of

\section{Dovepress}

urological disease; Pharmacology of drugs used for the treatment of urological disease. The manuscript management system is completely online and includes a very quick and fair peer-review system, which is all easy to use. Visit http://www.dovepress.com/testimonials.php to read real quotes from published authors. 